\title{
THE HISTORY OF THE GARDEN NARCISSI
}

\author{
ANN P. WYLIE \\ John Innes Horticultural Institutian, Hertfard
}

\section{CONTENTS}

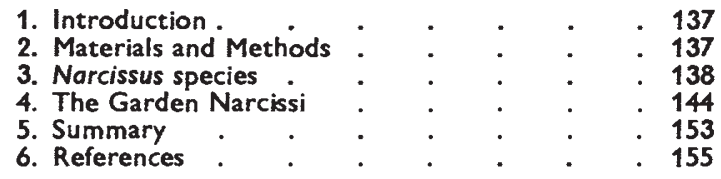

\section{INTRODUCTION}

THE object of the present study is to discover how far the study of chromosomes and a knowledge of hybridisation and documentary history can be used to reveal the origin and means of improvement of the garden daffodils. Previous cytological studies of the genus Narcissus have been made, principally by Fernandes (I934-I95I) and Nagao (I929, I933), both of whom considered the wild species for the most part. As a result of their labours, the cytological picture of the genus is now well established. There are two basic numbers: 7 is found in all the species except $\mathcal{N}$. tazetta and the closely related $\mathcal{N}$. elegans and $\mathcal{N}$. broussonetii, in which it is Io or the derived I I. Polyploidy is rare in the wild with the exception of $\mathcal{N}$. bulbocodium. Most of the apparently wild polyploids reported in the other species are not certainly known to be native in the places where they were collected and are probably escapes from cultivation.

The genus is confined to the temperate Old World, with its headquarters in the Iberian peninsula. The northern limit is England, the southern the Canary Islands, while Asia Minor and Syria probably represent the easterly extremes of distribution. $\mathcal{N}$. tazetta in its more easterly stations of Persia, Cashmir, China and Japan is doubtless subspontaneous only (Fernandes, I95I). Members of the genus have been cultivated for centuries and horticultural varieties have been created at an increasing rate since $185^{\circ}$, when a start was made with deliberate hybridisation. To-day there are over I2,00o named varieties. A list of the chromosomes numbers of a representative selection of these garden Narcissi has been published (Janaki-Ammal and Wylie, I949).

\section{MATERIALS AND METHODS}

Bulbs and flowers of $\mathcal{N a r c i s s i}$ were given me by the following, to whom I am most grateful: Col. F. C. Stern, Goring-by-Sea, Sussex; the Director and Dr E. K. Janaki-Ammal, R.H.S. Gardens, Wisley, Surrey; and W. O. Backhouse, Sutton Court, Hereford. Bulbs were also obtained from Messrs Barr and Son, W. Blom and A. Gray.

Somatic counts were made from root-tips, where possible, pretreated with mono- 
bromonaphthalene (O'Mara, r948), to which was added 'or \% of a wetting agent, sulphonate of lorol, to assist in penetration and shorten the time necessary for pretreatment. The root-tips were then fixed in acetic alcohol (figs. $\mathrm{r}, 5^{b}$ and $c, 9 a$ and $b$, $\mathrm{r} \mathrm{o} b$ and $\mathrm{r} \mathrm{r}$ ) or ${ }_{2} \mathrm{BE}$ (figs. 2, $5 a$ and $d, 6,9 c$, and $\mathrm{ro} a, c$ and $d$ ) and prepared as Feulgen squashes in the usual way. Where roots were not available, a useful source of mitoses proved to be nucellar and integumentary tissue in ovules from recently opened flowers. Strings of ovules were dissected out of the ovaries, pretreated and fixed as for root-tips and prepared as orcein or lacmoid squashes. Pollen grain divisions were obtained in aceto-carmine squashes of anthers fixed in acetic alcohol (figs. 8, 12) or else from smears fixed in $2 \mathrm{BE}$ and stained in Feulgen (fig. 7).

\section{NARCISSUS SPECIES}

\section{(i) General}

In order to give some idea of the sources of the garden narcissi of to-day, a brief survey of the species in the genus will be made, indicating the characters they have contributed to the various garden groups and the available cytological data.

As Fernandes (I95I) has shown, the use of the basic chromosome number and breeding behaviour in defining the main species provides a far more natural classification than any of the many schemes previously proposed (e.g. Baker, I 888). The major subdivision is in to the large group with 7 as the basic number and the smaller one of $\mathcal{N}$. tazetta and relatives in which it is Io or II. The former includes the whole of Baker's Magni- and Medio-coronatae and part of his Parvicoronatae and the latter the remainder of the Parvicoronatae.

In Table I the more important species are divided into groups according to their chief diagnostic characters. Brief notes on these sexual species are given below.

TABLE I

Principal characters of Narcissus species

\begin{tabular}{|c|c|c|c|c|}
\hline \multirow{2}{*}{ Corona } & \multirow{2}{*}{$\begin{array}{l}\text { Flowers } \\
\text { per } \\
\text { Spathe }\end{array}$} & \multicolumn{2}{|c|}{ Leaves } & \multirow{6}{*}{ 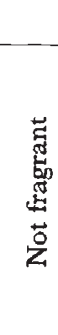 } \\
\hline & & Flat or linear & Cylindrical & \\
\hline \multirow[b]{2}{*}{ Long } & \multirow[b]{2}{*}{ one } & \multicolumn{2}{|c|}{$x=7$} & \\
\hline & & $\begin{array}{l}\text { pseudonarcissus } \\
\text { cyclamineus }\end{array}$ & $\begin{array}{l}\text { bulbocodium } \\
(2 x, 4 x, 6 x)\end{array}$ & \\
\hline Medium & two plus & & & \\
\hline \multirow{4}{*}{ Short } & \multirow{2}{*}{ one } & \multicolumn{2}{|c|}{ watieri } & \\
\hline & & poeticus & $\begin{array}{l}\text { rupicola } \\
\text { atlanticus }\end{array}$ & \multirow{3}{*}{ 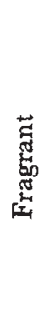 } \\
\hline & \multirow[b]{2}{*}{ two plus } & $x=10, x$ & calcicola & \\
\hline & & $\begin{array}{l}\text { tazetta } \\
\text { elegans } \\
\text { broussonetii }\end{array}$ & $\begin{array}{l}\text { fernandesii } \\
\text { juncifolius } \\
\text { gaditanus } \\
\text { jonquilla } \\
\text { viridiflorus } \\
\text { serotinus }\end{array}$ & \\
\hline
\end{tabular}




\section{(ii) Sexual Species}

I. $\mathcal{N}$. pseudonarcissus $L$., the common daffodil. Great variation is found in size and flower colour throughout its range and led Pugsley (r 933 ) to split it into 26 species. However, as A. and R. Fernandes (1946) point out, there is no justification for this from the cytological data. Practically all are diploids. The cultivated varieties hispanicus ( $=$ maximus) and tortuosus (Fernandes, A. and R., l.c.) are triploids, and bicolor is reported by the Fernandes as a tetraploid. Polyploids have arisen or at least have been preserved in cultivation. B chromosomes in several varieties (section iv).

2. $\mathcal{N}$. cyclamineus DC. is distinguished from the closely related pseudonarcissus by the longer corona and sharply reflexed perianth segments, a character which is dominant in crosses with other species and garden varieties. It has a very limited distribution in Portugal. Like pseudonarcissus, it is a diploid (A. and R. Fernandes, 1946) and cytologically indistinguishable from that species (fig. $\mathrm{I} b$ ). It is only recently that it has been used in hybridising with garden narcissi.
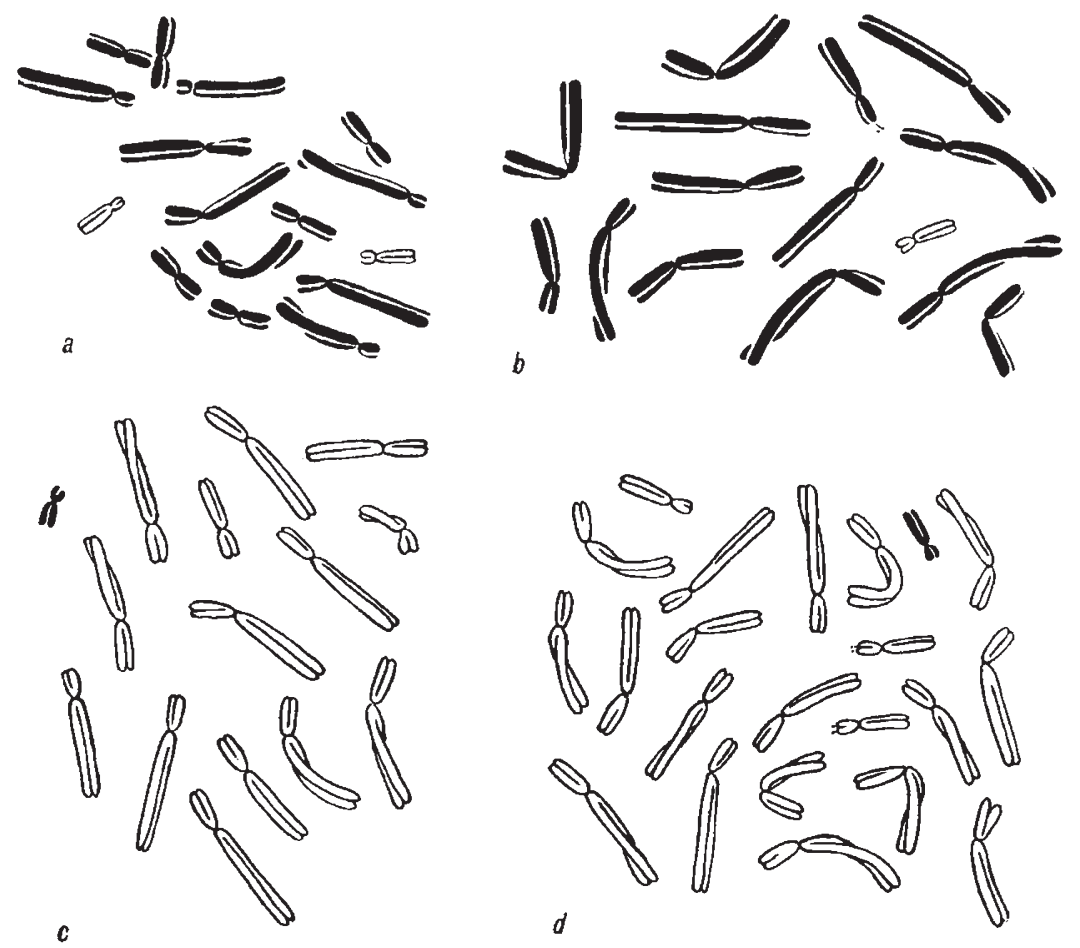

FIG. I.--Supernumerary chromosomes in root tip mitoses of species and hybrids.

(a) $\mathcal{N}$. bulbocodium citrinum, $2 n=14+2$ heterochromatic B's. (b) $\mathcal{N}$. cyclamineus, $2 n=$ I $4+$ I B. (c) $\mathcal{N} . X$ bernardi, $2 n=14+$ I B. $(d)$ the cyclamineus hybrid "Beryl" with $2 n=2 \mathrm{I}+\mathrm{I} \mathrm{B}$.

(a) and $(b) \times 2,200:(c)$ and $(d) \times 1,700$.

3. $\mathcal{N}$. bulbocodium $\mathrm{L}$. shows the maximum development of the corona in the genus. It is highly variable in size, colour and form and is the only species in which polyploidy is important. Fernandes (1947) has reported diploid to hexaploid varieties. I found 29 chromosomes in the recently introduced variety romieuxii from the Middle Atlas mountains, a previously unreported number for the species. The extra chromosome was an additional representative of one of the normal complement. This species has been little used so far in breeding garden narcissi, except for a few recent 
hybrids with such dwarf species as $\mathcal{N}$. triandrus and members of the jonquilla group.

4. $\mathcal{N}$. triandrus $\mathrm{L}$. is one of the group with more than one flower per scape (table I) and has a moderately developed corona. Again all the varieties are diploids (Fernandes, 1949). This species, too, has been used only recently for crossing with garden narcissi.

5. $\mathcal{N}$. poeticus $\mathrm{L}$. is second only to pseudonarcissus in its importance as an ancestor of the garden narcissi. It is widely distributed throughout S. and S.E. Europe and naturalised in many places elsewhere. It, too, is a variable species and has been split into 9 by Pugsley (1915). All forms so far examined are diploid, with the exception of the variety recurvus which I found to be triploid. No wild locality is known for this variety, however, (Pugsley, l.c.), and it is probably a garden escape like the polyploids in the pseudonarcissus complex. The main characters of this species are the one-flowered scape (table I), the uniformly white perianth segments, the long perianth tube and the disc-like corona, which is either suffused with a red or orange pigment or has this colouring restricted to a narrow rim. This pigment is the ultimate source of all the brilliant red and orange shades found in the modern garden clones.

6. $\mathcal{N}$. jonquilla L., with many flowered spathes and rush-like leaves, also has a short corona and very fragrant flowers. 7 allied species may also be included here, all dwarfs and of restricted distribution in the Iberian peninsula (Fernandes, I939c). All are diploids, including atlanticus, with the exception of viridiflorus, a tetraploid found near Gibraltar and on the Moroccan coast.

7. $\mathcal{N}$. tazetta L. is the principal species in the second main division of the genus, that with a basic number of 10 or 11 . It is found all round the Mediterranean, but the localities often quoted of Persia, Cashmir, China and Japan are probably only places where it has escaped from cultivation (Fernandes, I95I). Most of the plants of this species investigated by Nagao (1933) were polyploids, which is further evidence for regarding these Far Eastern "varieties " as garden escapes. $\mathcal{N}$. broussonetii Lag., from N. Africa, belongs to the white flowered group of tazetta varieties (Bowles, 1934) and is distinguished from all other species by the extreme rudimentary condition of the corona. Like the white flowered tazettas, it has 22 chromosomes. Also related to $\mathcal{N}$. tazetta is the autumn flowering $\mathcal{N}$. elegans Spach. with 20 chromosomes.

\section{(iii) Hybrid Species}

Cytological studies and controlled crosses have shown that a number of narcissi, originally considered distinct species, are really hybrids. Fig. 2 shows the relationships of the species concerned.

I. $\mathcal{N}$. bernardi DC. occurs wild in the Pyrenees wherever pseudonarcissus and poeticus overlap in distribution, and time of flowering (poeticus being, on the whole, some weeks later than the former). It varies according to the form of the parental species involved and is intermediate between them in such characters as the length of the perianth tube and of the corona. The one clone that I have examined was a diploid with $14+\mathrm{IB}$ chromosomes (Fig. Ic). $\mathcal{N}$. bernardi is the only fertile diploid hybrid species. Engleheart (1894) reports that among the progeny from bernardi selfed, forms were found which covered the whole range of variation from pseudonarcissus abscissus through bernardi to poeticus. $\mathcal{N}$. bernardi is the wild counterpart of the garden hybrids formerly grouped under $\mathcal{N}$. incomparabilis and now called the large-cupped narcissi.

2. $\mathcal{N}$. johnstonii Pugs. was discovered in 1885 in Portugal and later in Spain. On morphological grounds this species was considered to be a natural cross of triandrus and pseudonarcissus and similar forms were raised by Engleheart (189o) from crossing the triploid trumpet daffodil "Emperor" with triandrus. The clones examined by Philip (1934), Fernandes (1945) and me were all triploids. Since the hybrid looks more like pseudonarcissus than triandrus, it is likely that 14 chromosomes were contributed by the former rather than the latter parent, probably through a diploid gamete. 
3. $\mathcal{N}$. odorus $\mathrm{L}$. is presumably of ancient garden origin, since no wild locality is known for it. It is intermediate between pseudonarcissus and jonquilla and Herbert (1842) raised scarcely distinguishable plants by crossing these two species. Pereira (1940) found it to be a diploid in which chromosome types characteristic of the two supposed parents could be recognised. The very irregular meiosis that she found and its complete sterility give further evidence of its hybrid origin.

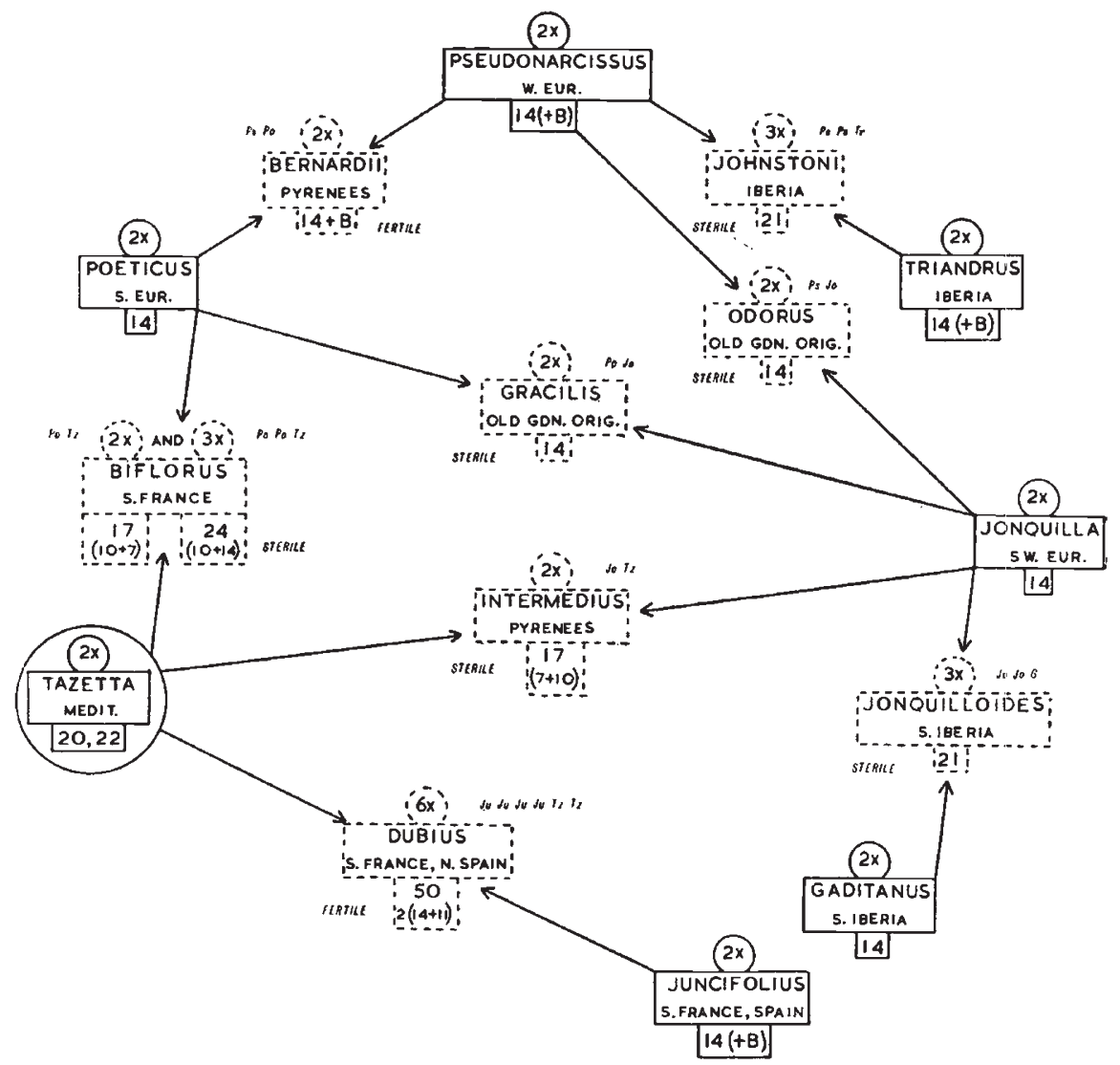

HYBRID SPECIES IN NARCISSUS

Fig. 2,-Diagram showing the natural interspecific hybrids which have been studied cytologically.

4. $\mathcal{N}$. gracilis Sab. and its variety tenuior Curt. also has no wild locality known. It combines the characters of jonquilla and poeticus and Engleheart (1894) by crossing these two species produced quite typical specimens of gracilis. Pereira (1940) reports that gracilis is a diploid and I have found the same for tenuior. Lack of pairing at meiosis and complete sterility again demonstrate its hybridity.

5. $\mathcal{N}$. intermedius Lois. is also supposed to have jonquilla as one parent. The other, on morphological grounds and as a result of Engleheart's crosses (1894), was considered to be tazetta. Nagao (1933) found it to have I7 chromosomes, with complete lack of pairing at meiosis and sterile pollen. It has been collected wild from the Pyrenees and is quite sterile.

6. $\mathcal{N}$. biflorus Curt. is considered to be the result of crossing tazetta and poeticus. It has been long cultivated, but the cross has apparently also taken place in the wild in the south of France (Bowles, 1934). It is intermediate in appearance between 
the supposed parents and was synthesised by Engleheart (1894). Nagao (1933) found it to have 24 chromosomes, which usually formed 7 bivalents and ro univalents at meiosis. Its formula is thus PoPoTz. Fernandes (I 934) reports a plant of this "species" with 17 chromosomes, which must then have arisen from the fusion of haploid gametes (PoTz). The two types are recognisable, as biflorus is reported as being sometimes much closer to tazetta than at others. It is again quite sterile.

7. $\mathcal{N}$. jonquilloides Willk. is a triploid (Fernandes, 1939a), found in the south of Spain and Portugal, where the distributions of jonquilla and gaditanus overlap. The morphological and cytological findings support the JoJoG formula. As no tetraploid forms of jonquilla have been found in the wild yet, a diploid gamete was probably involved. Trivalent formation at $\mathrm{MI}$ is common (Fernandes, l.c.).

8. $\mathcal{N}$. dubius Gouan is the only fully fertile hybrid species in Narcissus. I have confirned Fernandes' (1937a) rcport of $5^{\circ}$ chromosomes, the highest number yet found in the genus. It is a small tazetta-like plant found in the south of France and the N.E. coast of Spain. 'This distribution supports the idea, derived from the appearance of the hybrid and also chromosome morphology, that the parent species are juncifolius and one of the white varieties $(2 n=22)$ of tazetta. Fernandes suggests that it arose following chromosome doubling in a triploid hybrid with 25 chromosomes, I I from the tazetta parent and 14 from a diploid juncifolius gamete. Its formula would then be JuJuJuJuTz'Tz.

All the major species of Narcissus have therefore taken part in the origin of natural hybrids, with the exception of cyclamineus, which as we saw has a very limited distribution. There are also some additional species which are suspected to have a hybrid origin, but for which no cytological information is yet available. Details of these will be found in Fernandes (I95I). The ease with which interspecific hybridisation occurs in the genus has been of great importance in the development of the garden narcissi.

\section{(iv) B Chromosomes}

Individuals of several of these species have been found with one or more supernumerary or $B$ chromosomes. These float in populations of the sexual species or may be fixed in the clonal ones. They may or may not be heterochromatic. Table 2 gives a list of the species and also their associated garden varicties in which $B$ chromosomes are present. Since heterochromatin does not occur in any appreciable quantity in normal plants, it is easy to tell whether the $B$ chromosome is heterochromatic or not.

In all the species and varieties which I have found to contain $B$ chromosomes, this is easily recognised. It is about two-thirds the size of the trabant-bearing chromosome, normally the shortest in the complement, and it has a subterminal centromere (fig. I). All the $B$ chromosomes I have found are very similar and all euchromatic except for the two found in one plant of $\mathcal{N}$. bulbocodium citrinum (fig. I $a$ ). Two large chromocentres in the resting nuclei of this plant show that the $B$ 's are heterochromatic. In other varieties of the same species, Fernandes (I 947 ) has reported from I to $4 B$ 's, which may be either eu- or hetero-chromatic. The heterochromatic $B$ found by Fernandes ( $1939 b)$ in $\mathcal{N}$. juncifolius differs from those in the other species, in being nearly as large as one of the normal long chromosomes.

The $B$ 's found in the garden varieties listed in table 2 are all 
TABLE 2

$B$ chromosomes in Narcissus

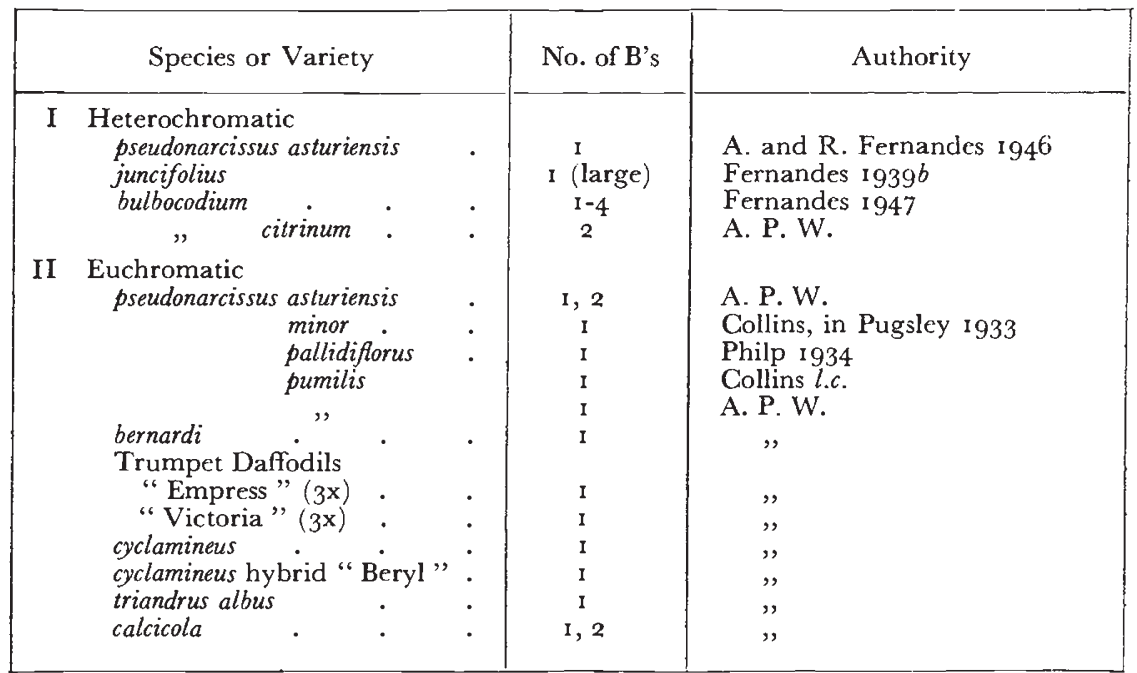

euchromatic and of the same type as those found in the related species and are presumably derived from them. The extra chromosome in "Empress" (fig. 3a) is therefore not a fourth representative of one of
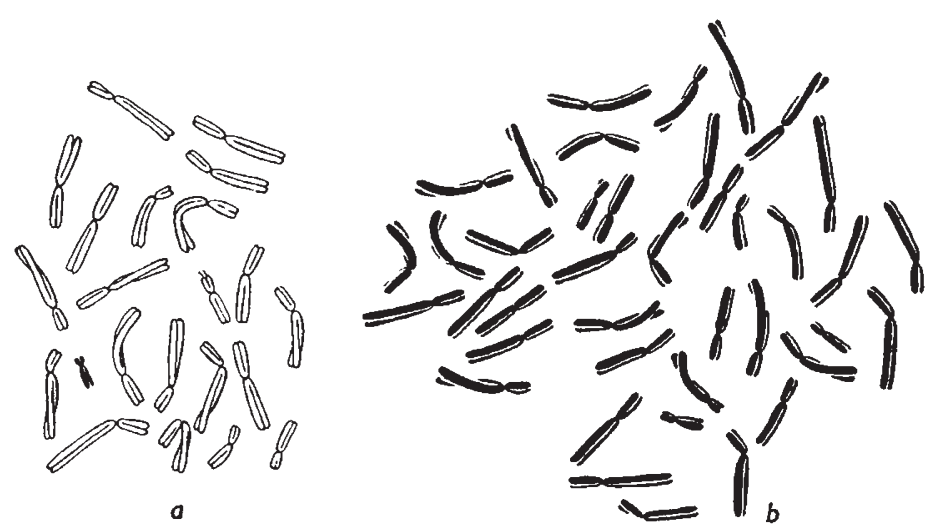

Fig. 3. - (a) Somatic chromosomes of the trumpet variety "Empress" with $2 n=21+1$ B. (b) root tip mitosis in a trumpet seedling with 4 I chromosomes. $\times 1,120$.

the longest chromosomes of the normal complement, as reported by the Fernandes (1946). The triploid bicolor trumpet "Victoria" also has a euchromatic $B$. Again the extra chromosome is not one of the normal, long chromosomes, as Sikka (I940) suggests. Two other triploid trumpets (now perhaps extinct), "Grandis" and "Horsefieldii" have been reported to have 22 chromosomes, by Nagao (1929) and by Philp (1934). Here also perhaps the extra chromosome is a $B$.

The cyclamineus hybrid "Beryl" (fig. I $d$ ) also has 22 chromosomes, 
of which one is a $B$ and similar to one found in a plant of $\mathcal{N}$. cyclamineus (fig. I $b$ ).

\section{(v) The Two Basic Numbers}

The chromosomes of the species with basic number 7 all have median or submedian centromeres (e.g. figs. I, 6b) with minor differences only between the complements of the different species (Fernandes, 195I). But in tazetta and relatives with basic number ro or I , 8 of these chromosomes have subterminal centromeres (fig. 6a). As Fernandes (l.c.) has shown, 7 is almost certainly the original number for the genus and so the derived one. The latter could have arisen from 7 by fragmentation near the centromere, as in Fritillaria (Darlington, I936).

I have examined material from Ciol. F. C. Stern of the closely related genus Tapeinanthus, with but one species, T. humilis, in S. Spain and Morocco. It is a tetraploid with $2 n=28$, the same basic number therefore as the larger section in Narcissus. Morphologically however the Tapeinanthus chromosomes, with most centromeres subterminal, are closer to those of the $x=$ Io (II) section of Narcissus. It forms a cytological bridge between the two sections and perhaps approximates to an ancestral condition from which these have subsequently diverged. There is no evidence so far that there has been a continuous series of basic numbers such as Neves (1939) reports for Leucojum. However the third genus in the tribe Narcisseae, Cryptostephanus, in which Gouws (1949) reports $2 n=24$ for the $\mathrm{S}$. Rhodesian $C$. vansonii, suggests the additional basic number for the tribe of $x=12$.

\section{THE GARDEN NARCISSI}

Narcissi have been cultivated since classical times, both as ornamental and medicinal plants, but the modern era in their horticultural development did not begin until the middle of last century, following the demonstration by Herbert ( 1843, r 847 ) of the possibilities of hybridisation. Fig. 4 shows the origin of the present-day groups of garden narcissi.

\section{(i) The Trumpet Group}

These are derived from members of the pseudonarcissus complex only. The first notable advance came in the I86os, when triploid clones appeared independently among the seedlings of three English breeders, Backhouse, Leeds and Horsefield. These however did not come into general cultivation until 1875 , when the collections of seedlings raised by these hybridisers were bought and classified by Barr (Barr, I933). Information about the precise origin of these first triploids is lacking, since none of these breeders left records of their crosses. However, a note by Backhouse (1865) throws a little light on the question. He writes:

" ... N. bicolor seeds badly and is deficient in pollen, but from crosses of other daffodils with it, I have raised some of the largest and finest in the class. These also seed badly ..." 
This reference to the sterility of bicolor (a variety of pseudonarcissus) suggests that he had a triploid clone of this variety although the Fernandes (1946) report it as a tetraploid. The result of crossing this

\section{ORIGIN OF THE GARDEN FORMS OF NARCISSI}

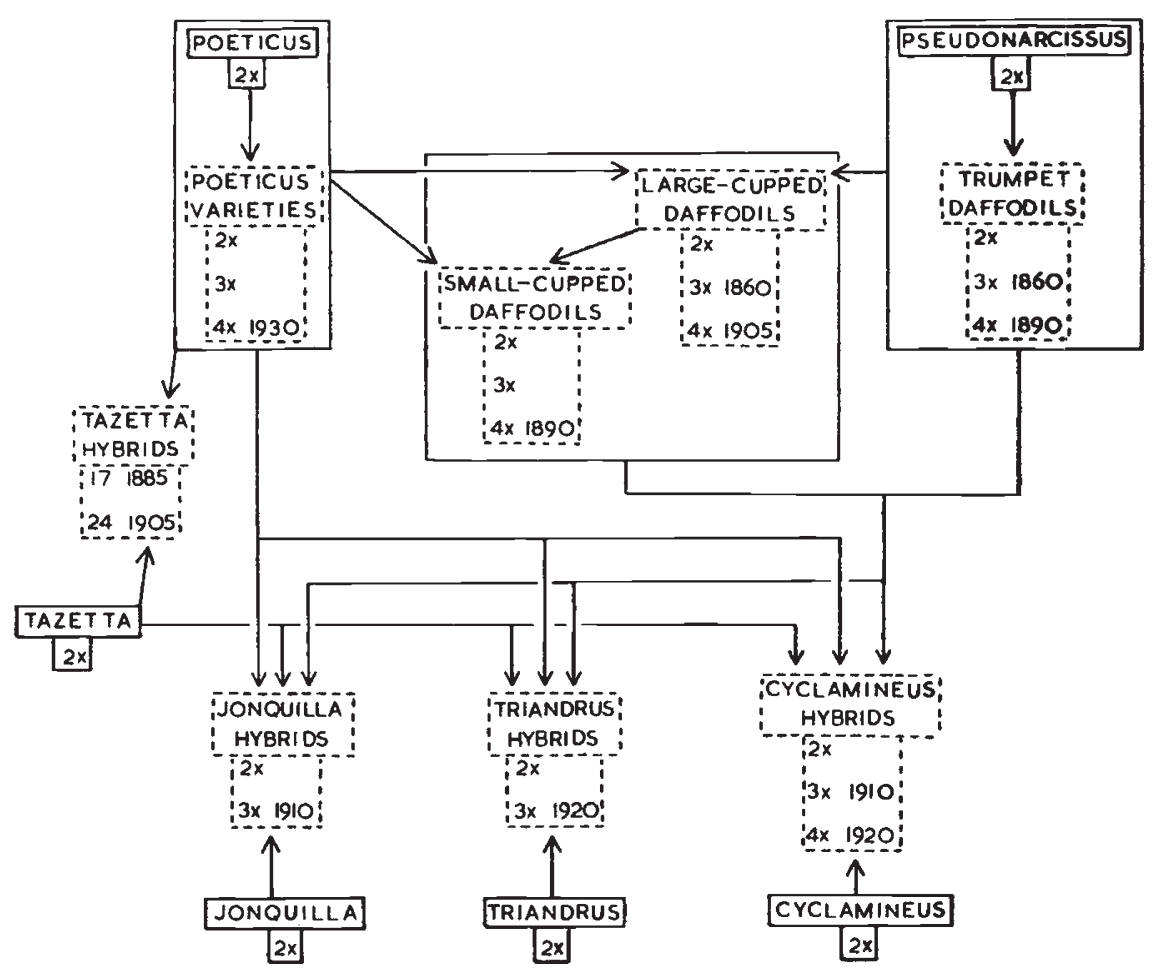

FIG. 4.-Diagram showing the origins of the main groups of garden narcissi.

triploid with a diploid variety of pseudonarcissus was to add the effect of hybrid vigour to that of polyploidy. The sister varieties " Emperor" and "Empress", raised by Backhouse, were as we have seen triploid and were a great advance on any daffodil cultivated up to that time.

The triploids were the beginning of the new era in daffodil breeding. The tetraploid clones arose from them in the r8gos. The well known yellow Trumpet "King Alfred" was one of the first and attracted much attention when first shown. Again, its origin is uncertain. It may be " Empress" crossed with $\mathcal{N}$. pseudonarcissus hispanicus (Williams, I929), both triploids. I have found tetraploids in a family raised from "Emperor" self-fertilised; this origin is therefore quite plausible. The Dutch variety "Van Waveren's Giant" (I900), introduced only one year later than " King Alfred", was found by de Mol (I923) to be a tetraploid also. The step from triploidy to tetraploidy evidently occurred independently at about the same time in the two main centres of daffodil breeding. 
The tetraploid trumpet daffodils wcre of course more fertile than the triploids, which were all that had been available for breeding up till igoo. The comparative sterility of the latter was well known, even if the reason for it was not. Thus Williams (I929) comments:

"... there was a far larger percentage of sterility in those days

(i.e. at the end of last century) amongst hybrids both in males and females than is the casc to-day."

His Darwinian explanation " that by selection we have largely eliminated that characteristic" is, however, the reverse of the truth: the fertiles inevitably arose from breeding the steriles.

Higher polyploids than tetraploids have not yet becn found among the registered varieties of trumpet daffodils. I have, however, found a near hexaploid with $4 \mathrm{I}$ chromosomes among self-sown seedlings at Wisley (fig. $3^{b}$ ). It was growing among a clump of an ordinary tetraploid bicoloured trumpet, which was presumably the parent, from which it was easily distinguished by the much smaller flowers and less robust nature.

It seems therefore, that the optimum level of polyploidy in Narcissus is the tetraploid one. De Mol's query (1923) as to "whether the number of chromosomes may go on increasing indefinitely" must be then, answered in the negative. His assumption that the " conspicuous differences in size and form " in varieties derived from the early tetraploids would also be found to be associated with a variation in chromosome number has also so far proved unfounded.

TABLE 3

Comparison of chromosome numbers in the tetraploid varieties and in their progeny

\begin{tabular}{|c|c|c|c|c|c|c|c|c|c|c|}
\hline & \multicolumn{8}{|c|}{ Chromosome number } & \multirow{2}{*}{ Total } & \multirow{2}{*}{$\begin{array}{l}\% \text { with } \\
2 n=28\end{array}$} \\
\hline & 24 & 25 & 26 & 27 & 28 & 29 & 30 & 31 & & \\
\hline \multirow[t]{2}{*}{$\begin{array}{l}\text { Registered jarieties } \\
\text { I Species-Trumpets } \\
\text { II Hybrids-Large- and } \\
\text { Small-cupped }\end{array}$} & - & - & $\cdots$ & 4 & 99 & 1 & - & - & $\begin{array}{r}43 \\
104\end{array}$ & $\begin{array}{l}86 \cdot 0 \\
95 \cdot 2\end{array}$ \\
\hline & 一 & - & $I$ & 6 & 136 & 2 & I & $I$ & $\mathbf{r} 47$ & $92 \cdot 5$ \\
\hline \multirow[t]{2}{*}{$\begin{array}{l}\text { Seedlings } \\
\text { 1. Trumpet selfed } \\
\text { 2. ", " } \\
\text { 3. Large-cupped open } \\
\text { pollinated }\end{array}$} & $\stackrel{1}{-}$ & 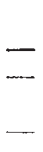 & - & $\begin{array}{c}18 \\
4 \\
4\end{array}$ & $\begin{array}{l}38 \\
10\end{array}$ & $\begin{array}{c}18 \\
1\end{array}$ & $\begin{array}{l}7 \\
1\end{array}$ & I & $\begin{array}{l}83 \\
16 \\
17\end{array}$ & $\begin{array}{l}43.5 \\
62.5\end{array}$ \\
\hline & I & - & 一 & 26 & 54 & 26 & 8 & $I$ & $\times 16$ & $4^{6 \cdot 5}$ \\
\hline
\end{tabular}

Table 3 shows the range in chromosome number found in the tetraploid trumpets, and also in the large- and small-cupped narcissi considered below. For comparison, the chromosome numbers found in families of seedlings from three different tetraploids are also included 
in the table. A much higher percentage of the registered varieties have the balanced number of 28 than is the case in the seedlings. The horticulturally desirable forms have thus been selected for the balanced tetraploid number. It is unnecessary to invoke a hypothetical pentaploid to account for the origin of "Madame de Graaff", a trumpet variety with 3 I chromosomes (Fernandes, I946), since I have found a plant with this number in the selfed progeny from a tetraploid (table 3 ).

Unfortunately the chromosomes cannot be divided into clearly differentiated classes, as they can in the hyacinths (Darlington, et al., 195I). Doubtless the apparently balanced number of 28 conceals in some cases variation in the proportions of the different chromosome types present, such as these workers have demonstrated in the polyploid hyacinth varieties.

Table 4 gives the chromosome numbers found in pollen grains at the first mitosis in six tetraploids ( 2 trumpets and 4 large-cupped).

TABLE 4

Chromosome numbers in pollen grains of tetraploid varieties

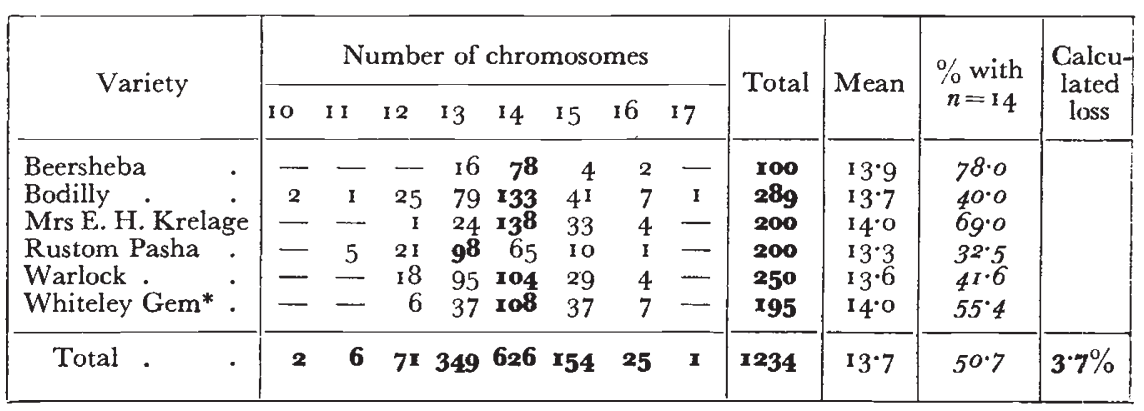

* excluding the unreduced pollen grains

The proportion of grains with 14 chromosomes varies rather widely but is of the same order as that of seedlings with 28 chromosomes. If the female gametes have the same variation in chromosome number as the male, then comparison of the figures for pollen grains and for seedlings shows that there has been some selection against the more unbalanced gametes at fertilisation. But selection at this stage is evidently not as stringent as that practised by the breeder.

\section{(ii) The Poet Group}

The only other group to be derived solely from one major species is the much smaller one from varieties of $\mathcal{N}$. poeticus intercrossed. Engleheart was the first to pay any attention to this group. His early hybrids, such as "Homer" and "Horace" were diploids like their parents, the varieties ornatus and poetarum. "Sarchedon", a later diploid, is illustrated in fig. $6 b$. I found two of the later hybrids (1927 and 1939) to be tetraploids; polyploidy has thus been a factor in the development of this group as well. So far the only triploid known is 
the variety recurvus, mentioned under the species. The recent tetraploids may therefore have arisen from the earlier diploid hybrids by chromosome doubling, as found by de Mol (1937) in one of the pseudonarcissus-poeticus hybrids, rather than by way of triploids, which seems to have been the more usual method in Narcissus.

\section{(iii) Trumpet-Poet Derivatives}

All the other horticultural groups of narcissi have arisen following crosses between major species or species complexes (fig. 4). $\mathcal{N}$. pseudonarcissus and $\mathcal{N}$. poeticus are the species responsible for the large groups of the large- and small-cupped narcissi, formerly known as the Incomparabilis and Barrii divisions respectively. The products of natural crosses had been cultivated for a long time with no idea that they were indeed of hybrid origin, until Herbert published his views. The first deliberate crosses with the aim of producing new garden varieties were made by Backhouse and Leeds ( $185^{\circ}-1860$ ), and introduced into commerce by Barr 20 years later. Again, imperfect records only were left and Engleheart (189o, I894), dissatisfied with this uncertainty, decided to try to recreate these early garden hybrids by means of controlled crosses, in the same way that Herbert had done for the hybrid species half a century earlier. This he accomplished, confirming and considerably extending Herbert's results.

The large-cupped narcissi are primarily pseudonarcissus $\times$ poeticus. They are intermediate between the ancestral species in such characters as the relative length of the corona, the length of the perianth tube and the way in which the stamens are inserted, while the distinctive red pigment found in most poeticus varieties as a narrow rim at the edge of the very shallow corona, has been the source of all the red and orange shades in the hybrids. As Anderson and Hornback ( 1946 ) have shown, this same red pigment from poeticus is one of the factors responsible for the development of the pink colouring found in some recent hybrids.

The small-cupped varieties arose in the first placc from backcrossing the large-cupped forms to poeticus, which they resemble in the length of the perianth tube and the obviously biseriate stamens (Engleheart, 1894). The small- and large-cupped classes may originally have been distinct, but after 70 years of hybridisation with each other and with the parental classes, there is now a continuous range between the two extremes.

Cytological data for the early representatives of thesc groups are meagre, but the outline is undoubtedly the same as for the Trumpet daffodils, with the early development of triploid clones, such as "Sir Watkin", followed in the I8gos by tetraploid ones. 'Thus the tetraploid "Albatross" arose from the triploid "Empress" crossed with $\mathcal{N}$. poeticus, presumably diploid (Bowles, r934), whilc de Mol (r937) reports one tetraploid which arose as a somatic mutation of a diploid. Again tetraploidy is the highest level of polyploidy found. Table 3 
shows that an even higher proportion of the large- and small-cupped narcissi than of the trumpet daffodils have the balanced chromosome number of 28 . Conformity to the tetraploid number is more rigorously enforced in varieties of hybrid origin than in those derived from pseudonarcissus only, as would be expected. It seems as though the plant cannot break two rules at once.

\section{(iv) Other Hybrid Derivatives}

Four other species have taken part in the development of garden narcissi, though to a lesser extent than the two considered above (fig. 4).

\section{(a) $\mathcal{N}$. cyclamineus}

Its hybrids are easily recognised, since the reflexing perianth segments of cyclamineus are usually present. It has been crossed with both diploids and tetraploids from the Trumpet and Large cupped groups, giving rise to diploid and triploid hybrids. "Minicycla" is an example of the former; it is from a cross with pseudonarcissus var. asturiensis $(2 x)$. "February Gold " and "Bartley" are examples of the latter, both of which have a yellow trumpet daffodil $(4 x)$ as the other parent.

I have also found one tetraploid, "Orange Glory", which is Dutch in origin. It is reported to be cyclamineus crossed with a yellow trumpet; possibly a diploid gamete of cyclamineus was responsible for the origin of this tetraploid which would have the formula PsPsCC and be fertile. Little further breeding has yet been done from these primary hybrids, although even the triploids are moderately fertile. Col. Stern has raised progenies from "Bartley". The seedling obtained from open pollination had 19 chromosomes, while two from a cross with the tetraploid large-cupped "Fortune" both had 26.

$\mathcal{N}$. cyclamineus has also been crossed with poeticus or its varieties. One such hybrid is the triploid "Beryl" already mentioned in the section on B chromosomes. Since it is a fairly old variety (1907), it is not likely that the poeticus parent was a tetraploid, so that one of the parents must have contributed a diploid gamete.

There is also a hybrid recorded from a cross with tazetta (var. "Soleil d'Or"), named "Cyclataz", which has I7 chromosomes. A diploid clone of "Soleil d'Or" must therefore have been the parent; I have found both diploid and triploid clones bearing this name.

\section{(b) $\mathcal{N}$. jonquilla}

Besides the ancient hybrids of jonquilla with pseudonarcissus and poeticus, known as $\mathcal{N}$. odorus and $\mathcal{N}$. gracilis (fig. 2), there is a group of recent hybrids, derived from crosses with the new polyploid garden clones (fig. 4). They are characterised by dark green, narrow leaves, two- or three-flowered scapes and highly fragrant flowers. Most are triploids, the other parent having been a tetraploid, for example "Trevithian". I have however found one tetraploid, "Yellow Prize", again of Dutch origin. 
The variety "Golden Perfection" has 3 I chromosomes (fig. $5^{b}$ ). Tazetta was evidently one of the ancestors from the form of the chromosomes. The number 3 I could have been achieved in either of two ways. An unreduced gamete in one of the triploid poeticus-tazetta $(2 n=24)$ hybrids, described below may have been fertilised by a normal jonquilla gamete $(n=7)$, giving a hybrid with the constitution JoPoPoTz.
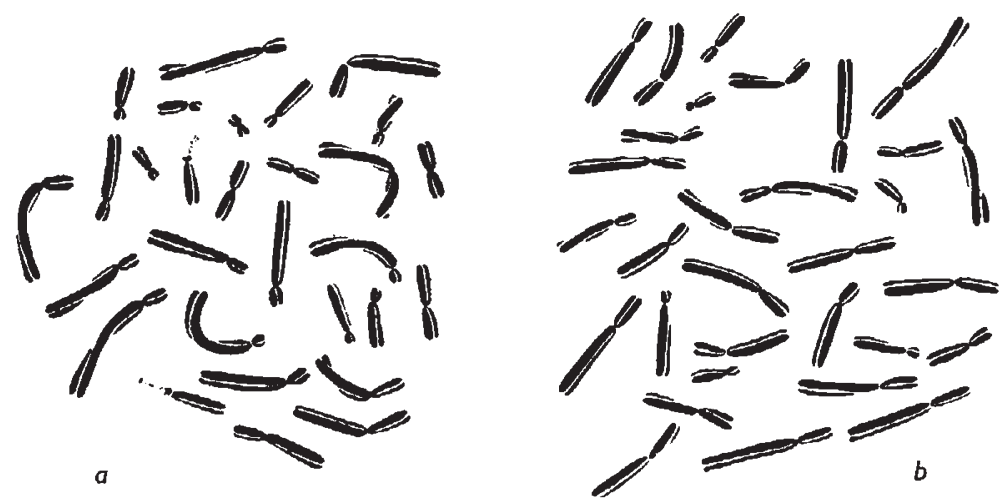

FIG. 5.-Root tip mitoses in two tazetta hybrids. (a) "Silver Chimes", triandrus $\times$ tazetta, with 29 chromosomes $(22+7)$. (b) "Golden Perfection", a jonquilla cross with 3 I chromosomes $(17+14$, or $24+7) . \times 1,75^{\circ}$.

Alternatively, the parents could be a diploid poctaz hybrid $(2 n=17)$ and $\mathcal{N}$. jonquilla, in both of which unreduced gametes were functional, producing the hybrid JoJoPoTz. The two cannot be distinguished cytologically, since the jonquilla and poeticus sets are alike in form.

Although a very distinct and desirable group of garden narcissi, no further breeding from these primary, mainly triploid, jonquil hybrids has yet been achieved, because of sterility (Wilson, 1948).

\section{(c) $\mathcal{N}$. triandrus}

The two- or three-flowered scapes and the drooping habit of the flowers with slightly reflexed perianth segments are characters of $\mathcal{N}$. triandrus usually found in its hybrids. There are small- and largecupped varieties, depending on the group to which the second parent belongs. "Hawera" (triandrus albus $\times$ jonquilla) has the anticipated diploid number and the rest, except the one considered below, are triploids and evidently crosses with tetraploid varieties from the other groups. "Silver Chimes" has 29 chromosomes (fig. 5a) and has tazetta as the other parent. This number may have been arrived at by the combination of 7 chromosomes from the triandrus parent and 22 from the tazetta, through a diploid gamete. Since the hybrid is white, the tazetta parent presumably was one of the series Albae (Baker, I 888), of which all examined have 22 chromosomes (Fernandes, I9376). As in the case of the jonquilla hybrids, sterility has proved an effective barrier to further breeding in this group. 


\section{(d) $\mathcal{N}$. tazetta}

The largest group of hybrids is derived from crosses with poeticus (fig. 4), corresponding with the natural hybrid $\mathcal{N}$. biflorus. A good many of these "poetaz" varieties were raised at the beginning of this century in Holland and subsequently in this country as well. CytoIogically the hybrids fall into two groups, with I 7 and 24 chromosomes respectively. Examples are "Geranium" (fig. 6c) and "Glorious"
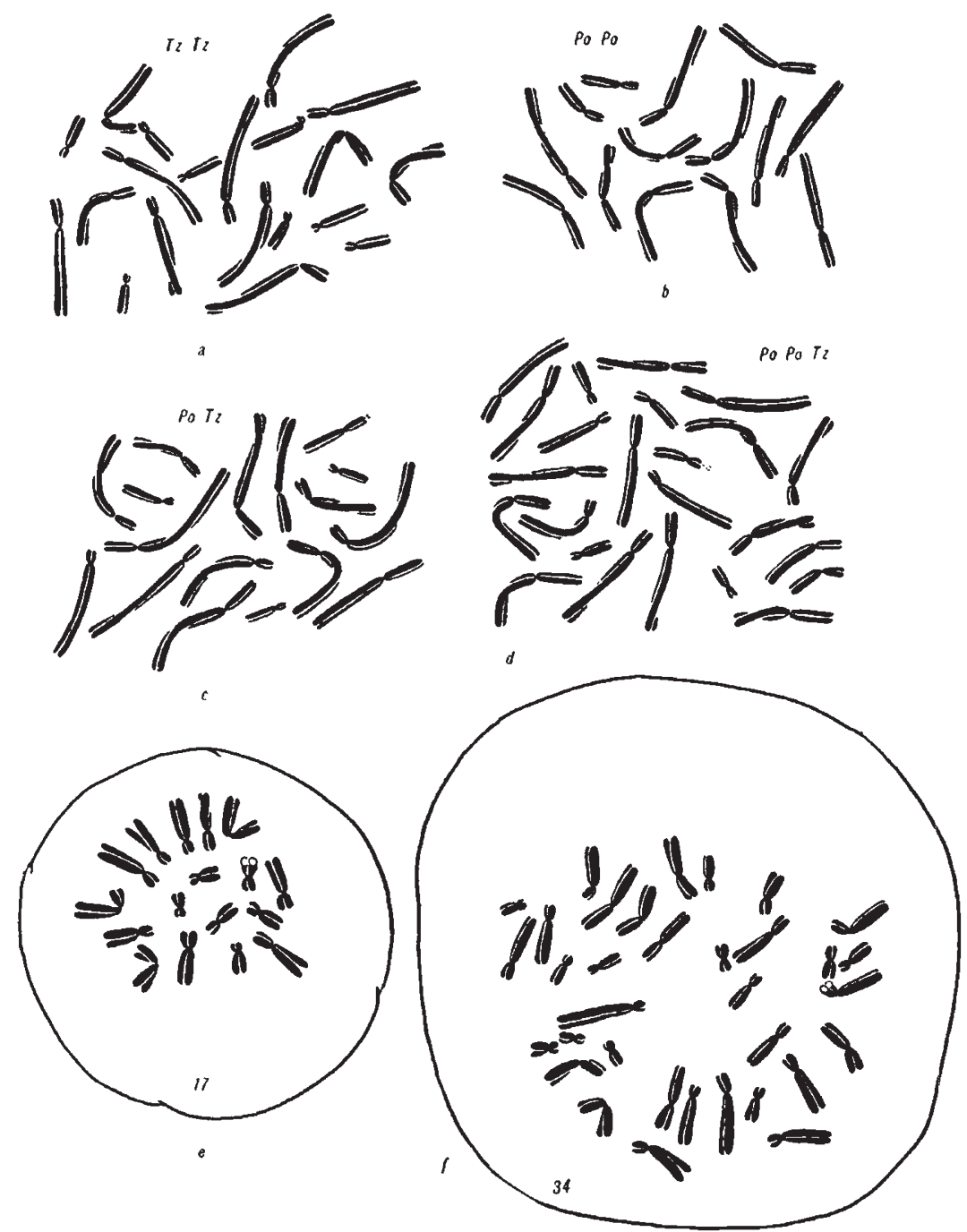

Fig. 6. - $\mathcal{N}$. poeticus, $\mathcal{N}$. tazetta and their hybrids. (a) the diploid tazetta " Soleil d'Or " with 20 chromosomes. (b) the diploid poeticus variety, "Sarchedon", $2 n=14$. (c) the diploid hybrid "Geranium" with 17 chromosomes $($ 1 $0+7) .(d)$ the triploid hybrid "Glorious" with 24 chromosomes (10 +14$).(e)$ and $(f)$ first pollen mitosis in "Geranium ": $(e)$ diploid grain with 17 chromosomes, $(f)$ a tetraploid one with 34 . $(a)-(d) \times 1,400 ;(e)$ and $(f) \times 1,050$. 
(fig. 6d). The first class arose from crossing diploid varieties of both species, while in the second either a tetraploid poeticus variety was used or unreduced gametes from a diploid. Like the natural hybrids between members of the 7 and Io series these garden hybrids are extremely sterile (Hannibal, I 945) and I have found no reports of their use in subsequent hybridisation, although, as noted above, there is cytological evidence that one of the 24 group may have taken part in the origin of the jonquilla hybrid "Golden Perfection".

"Geranium" is almost completely pollen-sterile and the only pollen grains which develop even as far as the first mitosis are those containing either 17 or 34 chromosomes (fig. $6 e$ and $f$ ), corresponding to the breakdown of one or both the meiotic divisions. Thus this variety provides a diagrammatic illustration of the principle that sterility is the result of segregation in a species hybrid.

\section{(v) General}

The main factors responsible for the development of this wide range of garden narcissi are, then, the following:

(a) The variability in nature of the species and species complexes.

(b) The ease of both inter- and intra-group crossing (Anderson, I948), which is reflected in the amount of natural crossing that has taken place, both in the wild and under cultivation.

(c) The fertility of crosses within and between the pseudonarcissus and poeticus complexes. With the exception of cyclamineus, which is very closely related to pseudonarcissus, other inter-group crosses have so far proved sterile.

(d) The development of polyploidy in all the groups of garden narcissi.

This last factor has been the most important. As noted previously, polyploidy is insignificant in the wild species, with the exception of bulbocodium, which has contributed practically nothing so far to the garden forms. However nearly all the Trumpet and Poet varieties and their hybrids introduced since I goo have been tetraploids. In a few cases these have arisen straight from diploids by means of a bud sport (de Mol, i 937). More commonly triploids are formed first, from which the tetraploids subsequently arise.

Unreduced gametes seem to be the principal way in which this has happened in both triploids and tetraploids. An extensive series was found in the tetraploid larg:--cupped variety "Whiteley Gem", in two anthers of one flower. Normal pollen grains had from I 2 to I 7 chromosomes (fig. $7 a$ and $b$, table 4 ) while corresponding with these was a series of giant pollen grains with even numbers of chromosomes from 24 to 32 (fig. $7 c$ and $d$ ). Again, failure of the second division must have occurred. In addition to these classes of dividing pollen grains, there was a further group of larger ones still, which had already completed their divisions and which were probably formed by failure of 
both meiotic divisions. They would be octoploid. In the poeticustazetta hybrids noted above, it is of course only the unreduced pollen grains which survive even till the first mitosis.

It is only the unreduced gametes produced by diploids, leading to the formation of triploids, and in these in turn producing the tetraploids, which have been functional so far. Those produced by the tetraploids themselves and by the poetaz hybrids have led to no further developments, with the exception of the hexaploid trumpet seedling from Wisley.
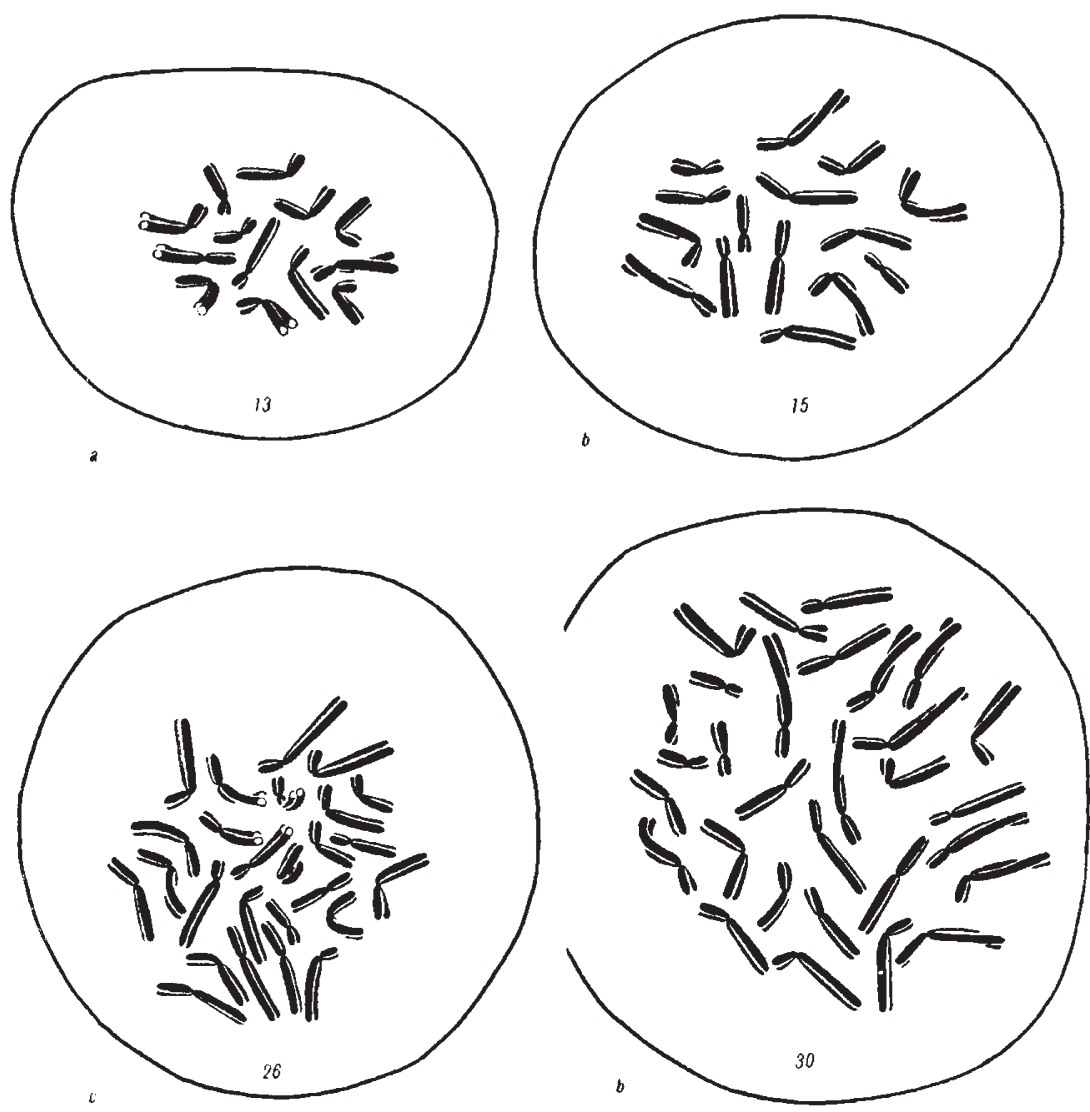

FIG. 7.-First pollen mitosis in the tetraploid large-cupped variety "Whiteley Gem". $(a)$ and $(b)$ haploid grains with 13 and 15 chromosomes respectively, $(c)$ and $(d)$ the corresponding unreduced grains with 26 and $30 . \times 1,050$.

\section{SUMMARY}

I. There are several types of species in Narcissus which can be distinguished cytologically:

(a) Sexually Reproducing: the basic chromosome numbers, io and I I , of the tazetta group set them apart from the rest of the genus with 7 . 
(b) Clonal Hybrids: all sterile.

(c) Fertile Hybrids: the partially fertile diploid bernardi, from pseudonarcissus $\times$ poeticus, and the fully fertile hexaploid dubius $\left(2 n=5^{\circ}\right)$, from chromosome doubling in a tazetta-juncifolius hybrid.

2. Supernumerary or $B$ chromosomes float in the populations of several sexual species and also exist in clones of some hybrid species and garden varieties. They may or may not be heterochromatic.

3. Polyploids are very few in Narcissus species but have been the main factor in the evolution of the garden varieties. During the last hundred years they have been the means of extracting from the species and species-hybrids new combinations of colour and form, on a larger scale of size. This process is still going on.

4. The modern garden trumpet daffodils are derived from crosses within the pseudonarcissus complex, accompanied by the development first of triploids in the I86os and then of tetraploids in the 1890 . Higher polyploids have been found only among seedlings, and seem to have exceeded the optimum level of polyploidy for the group. $\mathcal{N}$. poeticus is the other major species which has contributed most to the development of the garden narcissi.

5. Crosses between the two groups gave rise to the intermediate large-cupped narcissi, while the small-cupped group followed from backcrosses to poeticus. In all groups first triploids and then tetraploids appeared. .

6. The unselected progeny of tetraploids contain more aneuploids than are found in the varieties finally introduced. Selection for the balanced number of 28 is stronger in the hybrid groups of large- and small-cupped narcissi than in the trumpet daffodils, derived from one species only.

7. Besides these main groups of garden narcissi, all freely interbreeding, there are smaller groups derived from crossing these with the species cyclamineus, jonquilla, triandrus and tazetta. The cyclamineus hybrids are partially fertile, but the other three groups are sterile and breeding in these has not yet gone beyond the first crosses.

8. In a diploid poetaz variety, $2 n=17$, the only pollen grains to develop as far as the first mitosis were unreduced ones with 17 or 34 chromosomes - a diagrammatic illustration of the principle that sterility is the result of segregation in a species hybrid.

9. The newer groups of garden Narcissi may be expected to follow the course already described for the older groups, with increasingly diversified results.

Acknowledgments.--I am deeply indebted to Dr G. D. Darlington, F.R.S., for valuable advice. Most of the work was done while the writer was the holder of a post-graduate scholarship of the University of New Zealand. 


\section{REFERENCES}

ANDERSON, E. 1948. Hybridisation of the habitat. Evolution, 2, I-9.

ANDERSON E., AND HORNBACK, E. 1946. A genetical analysis of pink daffodils:

a preliminary attempt. Four. Calif. Hort. Soc., 7, 334-344.

Back house, w. i 865 . Gard. Chron., 530.

BAKER, J. G. I 888 . Handbook of the Amaryllideae. London.

BARR, P. R. I933. The renaissance of the daffodil in Britain. R.H.S. Daffodil Year Book, 4, $21-36$.

BOWLES, E. A. 1934. A handbook of Narcissus. London.

BURBIDGE, F. W. $\quad$ i 889. The Narcissus. Four. R.H.S., 11 , 70-92.

BURbidge, F. W. I 89o. Notes on the history of cultivated Narcissi. Four. R.H.S., I2, 296-3II.

coleman, c. J. I939. Ancestors. R.H.S. Daffodil Year Book, 1o, 5-9.

DARLington, c. D. 1936. The external mechanics of the chromosomes. P.R.S., $\mathrm{B}, 121,264-319$.

DARLINGton, C. D., HAIR, J. B., AND HURCOMBE, R. I95I. The history of the garden hyacinths. Heredity, 5, 233-252.

ENGLeHEART, G. H. 1890 . Seedling daffodils. Four. R.H.S., I2, 316-322.

ENGleheart, G. H. I894. Hybrid Narcissi. Jour. R.H.S., I7, 35-44.

FERNANDEs, A. 1934. Nouvelles études caryologiques sur le genre Narcissus L. Bol. Soc. Brot., II, 3-20I.

Fernandes, A. 1937a. Sur l'origine du Narcissus dubius Gouan. Bol. Soc. Brot., I2, 93-1 18.

FERNANDEs, A. 1937b. Le problème de Narcissus tazetta L. I. Les formes à 22 chromosomes somatiques. Bol. Soc. Brot., 12, 159-219.

FERnANDES, A. 1939a. Sur l'origine de Narcissus jonquilloides Willk. Scientia Genetica, $I, 16-6 \mathrm{I}$.

FERNANDES, A. 1939b. Sur le comportement d'un chromosome surnuméraire pendant la mitose. Scientia Genetica, I, 14 1-167.

FERNANDES, A. 1939c. Sur la caryo-systématique du groupe Fonquilla du genre Narcissus L. Bol. Soc. Brot., $13,487-544$.

fernandes, A. 1945. Sôbre a origem de Narcissus Fohnstoni Pugsley. An. Jard. Bot. Madrid, 6, I 45-158.

FERnANDEs, A. 1947. Summary of work on the cytology of Narcissus L. R.H.S. Daffodil and Tulip Year Book, 13, 26-34.

FERnANDEs, A. I949. Sur la caryo-systématique de la section Ganymedes (Salisb.) Schult. f. du genre Narcissus L. Bol. Soc. Brot., 23, I 77-2 18.

FERnANDES, A. 1950. La meiose chez Narcissus poetaz "Alsace". Genetica Iberica, 2, $149-174$.

FERnandes, A. 1951. Sur la phylogenie des especes du genre Narcissus L. Bol. Soc. Brot., 25, I1 3-19o.

FERNANDEs, A. AND R. I946. Sur la caryo-systématique du sous-genre Ajax Spach du genre Narcissus L. Acta Univ. Conim., I-33.

Gouws, J. B. 1949. Karyology of some South African Amaryllidaceae. Plant Life, $5,54-8 \mathrm{r}$.

hannibal, L. S. 1945. Tazetta hybrids. Plant Life, I, 24-26.

HERBERT, w. $1843 . \quad$ Hybrid Narcissi. Bot. Reg., n.s. $16,{ }_{3}^{8}$.

HERBERT, w. i 847. On hybridisation amongst vegetables. Four. Hort. Soc., 2, 1-28.

JANAKI-Ammal, E. K., AND WYlie, A. 1949. Chromosome numbers of cultivated Narcissi. R.H.S. Daffodil and Tulip Year Book, 15, 33-40.

DE MOL, W. E. 1923. The disappearance of the diploid and triploid Magnicoronatae Narcissi from the larger cultures and the appearance in their place of tetraploid forms. K. Akad. Amst. Proc. Sect. Sci., 25, 2 16-220. 
DE MOL, W. E. I937. D'un hybride d'espèces de Narcissus et de sa mutation somatique à la duplication du nombre des chromosomes et des nucléoles. Cytologia, F.7.N., 633-63o.

NAGAO, s. I929. Kariological studies of the Narcissus plant. I. Somatic chromosome numbers of some garden varieties and some meiotic phases of a triploid variety. Mem. Coll. Sci. Kyoto Imp. Univ. Ser. B, 4, 175-198.

NAGAO, S. 1933. Number and behaviour of chromosomes in the genus Narcissus. Mem. Coll. Sci. Kyoto Imp. Univ. Ser. B, 8, 81-200.

NEVES, J. B. 1939. Contribution à l'étude caryologique du genre Leucojum L. Bol. Soc. Brot., 13, 545-572.

o'marA, J. G. I948. Acetic acid methods for chromosome studies at prophase and metaphase in meristems. Stain Technol., 23, $201-204$.

PEREIRA, A. DE L. I940. Sôbre a cariologia de Narcissus odorus L. e $\mathcal{N}$. gracilis Sab. Bol. Soc. Brot., 14, 67-96.

PHILP, J. 1934. Narcissus chromosome numbers. R.H.S. Daffodil Year Book, 5, $52-53$.

PUGsley, H. W. 1915. Narcissus poeticus and its allies. Four. Bot., suppl. 2.

PUGsley, H. w. 1933. A monograph of Narcissus, sub-genus Ajax. Jour. R.H.S., 58, I $7-93$.

sikKa, s. M. 1940. Study of the somatic chromosomes in Narcissus. Ann. Bot., n.s. $4,427-464$.

stebbins, G. L. 1950. Variation and Evolution in Plants. Oxford University Press.

williams, P. D. I929. The progress of the daffodil from 1890 to 19 ro, in Daffodil Growing for Pleasure and Profit, 233-238. ed. A. F. Calvert. London.

williams, P. D. 1935. British daffodils-past and present. R.H.S. Daffodil Year Book, 6, 8-19.

WiLson, G. L. I938. Some pedigress. R.H.S. Daffodil Year Book, 9, ro-2 I.

wiLson, G. L. 1948. Notes on daffodil breeding. Herbertia, r3, 13-33. 